\title{
A Systemic Study of South African Emigrants' Experience OF The Canadian Environment
}

\author{
CORNEL RADEMEYER, CLAIRE WAGNER and NAFISA CASSIMJEE
}

\section{ABSTRACT}

The aim of this study was to investigate the coupling between the immigrant and the new environment by focusing on South African emigrants in Canada's experience of the environment. Thus far, acculturation and adaptation research has excluded the physical environment as a study unit. This study focused on the immigrants' adaptation as a whole by including the physical environment as a component of the acculturation and adaptation processes. Systems theory constituted a framework for studying the interactions between people, culture and the physical environment. Twenty-four interviews were conducted via the Internet. The first order analysis identified 36 categories of experience. The second order analysis identified nine pattern categories that constitute a shared experience. The third order analysis placed the immigrants' experience as a whole in the context of interacting systems. In conclusion recommendations are made for interdisciplinary co-operation, further research and the practical implementation of migration research.

Keywords: emigrants, place attachment, systems theory, adaptation

\section{Introduction}

To move from one place to another is not an unusual phenomenon, rather human beings have been moving about throughout the ages. It seems, however, that international migration is on the increase (Lorant, van Oyen and Thomas, 2008). Castles and Miller (2003: 7) describe this increase in international migration as 'part of a trans-national revolution that is reshaping societies and politics around the globe'. In keeping with the global trend, the emigration statistics of South Africa have also increased dramatically over the last few years (Statistics South Africa, 2003). In 2003 the number of selfdeclared emigrants was $48.4 \%$, higher than that of 2002 and the number of self-declared emigrants increased from 10890 in 2002 to 16165 in 2003.

Emigration impacts on many aspects of a person's well-being and the focus on the psychological impact of migration is not new. Many recent studies have focused on the impact of relocating (Karanth, 2007; Schmidt-Soltau and Brockington, 2007; Martikainen, Sipilä, Blomgren and van Lenthe, 2008). Others have focused on adaptation and acculturation strategies and processes (Berry, 2001; Berry, 2005), coping strategies and acculturation stress (Kosic and Triandafyllidou, 2003; Berry, 2005; Castellanos, 2006) and the physical, social and psychological adaptation of migrants (Ataca and Berry, 2002; Ward and Styles, 2003; Lorant et al., 2008). However, most of these studies have investigated learning and adapting strategies to the social, political and economic conditions of the new society. A decade ago Ng (1998) argued that the environment as a study-unit has been excluded from migration and acculturation studies. More recently, Brehm (2007) notes the paucity of a history of research on how the natural environment mediates community attachment and Knez (2005) observes that climate as an aspect is neglected in theoretical writing about place.

Two ideas espoused in systemic theory are of particular importance for this study. The first idea is that of interrelated systems, part-systems and sub-systems. In this study the environment was conceptualised as part of a complex interrelated system of form and process. In this way the processes of adaptation to the new environment as a whole, including the physical, social and economic environments were explored. Secondly, the implications of structural coupling (Keeney, 1983; Maturana and Varela, 1987), that involves the process of change and adaptation, will also be discussed.

\section{Human-environment system in a cultural context}

Jordaan and Jordaan (1998) argued that human experiences and actions could be studied by means of the contextual analysis and synthesis of part-systems and sub-systems. They differentiated between the biological part-system, the intrapsychic part-system, the ecological part-system and the metaphysical part-system for studying the human mind and behaviour. For the purposes of studying South African emigrants' experience of the Canadian environment, boundaries were drawn around the intrapsychic part-system (psychological processes) and the ecological part-system (physical environment and culture). These two part-systems form the human-environment system that reflects the interaction between humans and the environment: human society's activities affect the environment and the environment places constraints on society. However, this is not a simple cause and effect relationship. It is necessary to understand the complex interactions between society and the environment (Fraser et al., 2003); this relationship should thus be referred to as a transaction.

Jordaan and Jordaan (1998) further identified five sub-systems that constitute the intrapsychic part-system, of which the whole is bigger than the sum of its parts. These five sub-systems are the perceptual sub-system, the cognitive sub-system, the emotive sub-system, the dispositional sub-system and the self as sub-system. For the purposes of this study these five sub-systems are used to frame human experiences of the new environment.

Immigrants are confronted with perceptual experiences of the new environment. When encountering a new environment people's senses are often overwhelmed and they selectively 
perceive the information that has value and meaning to them (Golledge, 1987; Bell et al., 2001). In time, based on these attached meanings and values, their perception of the environment can change as modifications in meaning and value occur. The information that humans gather via perceptual observation is coded and sorted to form a cognitive model of the external world (Golledge, 1987; McDonald and Pelligrino, 1993). An individual's cognitive experience of the environment informs the cognitive processes whereby context and meaning are assigned to the external world.

Cultural experiences can also contribute to the meaning assigned to the environment and thus which perceptual information will be included in the cognitive structure (Golledge, 1987; Ng, 1998). Cognitive systems regulate human interaction with the environment and are thus important for everyday functioning and survival (Golledge, 1991; Jordaan and Jordaan, 1998; Zimring and Dalton, 2003). $\mathrm{Ng}$ (1998) is of the opinion that there is a shortage of information on immigrants' cognitive experiences of the new physical environment (which includes the built and the natural environment (Altman and Chemers, 1980)). The immigrant must adapt his or her cognitive system in order to incorporate the physical, social and psychological components of their new environment. The immigrant's cognitive system also adapts to incorporate the new cultural context, which in turn creates new rules for interactions with the environment.

According to Rapoport (1982) the evaluation of an environment depends more on emotional response than on a detailed analysis of the environment's specific components. Ulrich (1983) concurred with this idea of the emotional experience of the environment and argued further that the first reaction to an environment is emotional in nature. The nature and intensity of this first environmental experience can lead to further cognitive evaluations of the environment. A positive experience of the environment can lead to further exploration where a negative experience can lead to avoidance behaviour. The emigrants' first emotional experiences of the new environment may, in a similar manner, influence their involvement and adaptation to the new environment. The dispositional sub-system also contributes to environmental experiences. The context of a person's goals, purposes and motivations, based on his or her sensory contact with the environment, gives meaning to that environment (Amedeo, 1993). Wapner et al. (1973) argued that the immigrant does not enter his or her new environment as a passive agent, but has certain expectations and tentative plans for how he or she is going to reach his or her goals in this environment. These goals may even be achieved beyond the immigrant's expectations (Berry, 2006b).

The environment can also be experienced as an extension of the self to such an extent that perceived changes in the environment (Savage, 2008) or leaving that environment can lead to feelings of loss, as if the person has given up something of himself or herself. Intense emotional involvement with the old environment (nostalgia) can lead to feelings of rootlessness and this can have implications for the development of place attachment in the new environment (Jordaan and Jordaan, 1998; Ward and Styles, 2003).

\section{The physical environment as a context for human experiences}

The built environment creates a social context in which humans act and assign meaning (Wapner et al., 1973; Rapoport, 1982; Brehm, 2007). A reciprocal relationship exists between humans and the built environment. Humans design and build the environment according to social and cultural values and practices. Reciprocally, the built environment provides cues for social actions and cultural considerations (Rapoport, 1982; Ng, 1998). Immigrants have to learn how to discern the codes of conduct reflected in the built environment. If this learning takes place in an early life phase it is referred to as enculturation. When learning occurs later in life, such as after migration or through other processes of contact between two cultural groups this is known as acculturation (Berry, 2005). At times the immigrant may misinterpret these cues and behave in an inappropriate way $(\mathrm{Ng}, 1998)$, but people are usually able to adapt and personalise their new environment (Rapoport, 1982). This may also be related to psychological acculturation which refers to psychological changes on the individual level (Berry, 2001). Jordaan and Jordaan (1998) argued that environmental experiences may be based on the experience of the environment as a physical place with certain attributes and characteristics, which may contribute to the way an immigrant experiences the environment and thus adapts and acculturates.

Regarding the natural environment, the immigrant has to adapt him or herself to the new country's ecology of ideas regarding nature. An "ecology of ideas" refers to people's conceptions of their relationships with the natural environment (HarriesJones, 2005). This may pertain to seasonal and climate changes and the adaptations people have to make when migrating from the Southern to the Northern Hemisphere. Humans evaluate their environments in terms of certain attributes in order to determine environmental preferences (Golledge, 1991; Kaplan, 1991; Stedman, 2003). The immigrant takes with $\mathrm{him} /$ her certain preferences for certain types of environments. The extent to which the new physical environment complies with the immigrant's preferences may contribute to the adaptation and acculturation processes. The changes in the physical environment that South African emigrants to Canada face include the loss of identification with one's surroundings and being in a recognisable place and the differences in climate such as the cold, long winters and reversal of seasons between the Northern and Southern hemispheres.

\section{Place attachment}

Place can refer to the physical qualities of an environment as well as the bond that exists between an environment and society (Relph, 1976; Altman and Low 1992; Hidalgo and Hernandez, 2001; Brehm, 2007). In geography, the notion of place links natural and social science conceptions of the environment. The bond between the natural (physical environment) and the social (human society) is referred to by environmental psychologists as 'place attachment' and by geographers as 'sense of place' (Brown and Raymond, 2007). Evidence of geographers studying sense of place can be found in ancient Greek writings and in the 1970s and 1980s the sub-field of humanistic geography refocused the discipline's attention on the centrality of place and sense of place in understanding human existence (Windsor and McVey, 2005). Current research on sense of place examines the relationship between 
the meanings that people attach to places, how these meanings influence their perceptions of environmental conditions and how they react to ecological problems (Brown and Raymond, 2007).

Place attachment, or sense of place, may be associated with positive emotional experiences, identification with the environment, rootedness, feelings of belonging and being at home, knowledge of the environment and concern for the environment (Relph, 1976; Altman and Low, 1992; Vorkinn and Riese, 2001; Ward and Styles, 2003; Markovitzky and Mosek, 2005; Brehm, 2007). Savage (2008: 152) uses the term 'elective belonging' to refer to people's definition of a place 'belonging' to them, as the conscious choice to move to and settle in a particular place, a cognition that is probably applicable to many South African immigrants in Canada. An individual's experiences of place can create multiple attachments in one lifetime. Feldman (1996) argued that old attachments are not necessarily discredited by the development of new ones, possibly giving rise to ambiguous experiences of place attachment.

\section{Acculturation and adaptation}

Migration implies a change in physical, social, political and economic environments. The immigrant has to undergo changes in order to adapt to these environments. Emigration is a life situation that creates disturbances in both the immigrant and the new surrounding environment (Berry, 2001). It is in this context that both the immigrant and the new environment undergo changes in their structural components in an effort to adapt to each other. Maturana and Varela (1987) call this tendency of a system to change in an effort to fit itself to other systems, structural coupling. Therefore structural coupling is the way that two systems interact and fit in a symmetrical and complementary way. This implies continuous changes (adaptation) to enable the systems to become coupled and to stay coupled. In terms of acculturation literature this process of structural coupling is reflected in the processes of acculturation and adaptation.

Acculturation focuses mainly on the effect of cross-cultural contact and the processes involved in this contact and thus in learning a new culture (Berry, 2001). Culture can be seen as a context for human functioning. For this reason literature regarding acculturation involves the political, social, economic and physical environment (Berry, 1997; Ng 1998; Berry et al., 2002). One of the key factors in an immigrant's ability to acculturate to the new environment is the coping strategy that he or she employs (Kosic and Triandafyllidou, 2003; Ward and Styles, 2003; Berry, 2006b). Coping strategies refer to the cognitive and behavioural efforts that a person uses to address the stresses that he or she experiences and this can be seen as an effort to lessen or eliminate the effect of stress on overall well-being (Edwards, 1992). In developing the "Cybernetic Coping Scale", Edwards (1992) identified five types of coping strategies. These five ways of coping with stress are based on the notion that stress is a discrepancy between an individual's perceptions and disposition, given that the individual views this discrepancy as important. Coping strategies can improve well-being directly or can improve well-being by changing the determinants of stress. Bennet, Rigby and Boshoff (1997) used the five coping strategies identified by Edwards (1992) to analyse the qualitative data gathered for their study about the relationship between tenure, stress and coping strategies of South African emigrants to New Zealand. These five coping strategies are accommodation, changing the situation, devaluation, avoidance and symptom reduction. They found that both immigrants that had immigrated less than five years before and long-term immigrants (more than five years before) used accommodation as a coping strategy. In addition to accommodation both groups used changing the situation and then avoidance as coping strategies. Devaluation and symptom reduction were used to a lesser extent by both groups.

Adaptation can be seen as the end process of acculturation and can be defined as 'relatively stable changes that take place in an individual or group in response to external demands' (Berry, 2005: 709). Adaption does not necessarily improve the fit between individual and environment, have a positive outcome or lead to assimilation (when one becomes more like one's environment), but can entail resistance, attempts to change the environment or separate oneself from the environment (Berry, 2005). Berry (1997) made a distinction between psychological, socio-cultural and economic adaptation. Research and literature on adaptation after emigration focuses mainly on the immigrant's social and cultural adaptation, as well as the new society's attitude and political policies surrounding emigration (Berry et al., 2002; Bakker et al., 2006). The literature also focuses on the economic adaptation of the emigrant (Aycan and Berry, 1996; Reitz and Sklar, 1997; McNeece, 2002). Little, if any, literature focuses on the immigrant's adaptation to the physical environment $(\mathrm{Ng}, 1998)$. The aim of this exploratory study was to understand and describe the role that the physical environment plays in a South African emigrant's experiences of and adaptation to a new environment. The integration of the physical environment as a component in acculturation studies can enhance the framework that is used in future research.

\section{Method}

\section{Procedure}

The South African Network of Skills Abroad (SANSA) was used as a means to make contact with South African emigrants in Canada. SANSA is a website that was hosted by the University of Cape Town and has been the responsibility of the National Research Foundation (NRF) since October 2000. According to the NRF website this site connects skilled people living abroad with local experts and projects. This website consists of a database of South African professionals who have emigrated and who are willing to interact via the Internet with South African professionals. This website facilitates interaction by informing its members of the specific needs or requests of South African professionals. Searching the SANSA database for South Africans in Canada delivered 110 contact persons. In order to ensure the anonymity of the database subscribers the researcher did not contact the potential participants directly; email was sent to these persons via the SANSA website. This email contained a description of the study and requested willing participants to contact the researcher via e-mail.

\section{Sample}

Forty-four South Africans (all previously classified as white) in Canada answered the e-mail, indicating their willingness to participate in the study. The final study included four interviews using an Internet relay chat program and 20 e-mail questionnaires. The participants' ages ranged from 34 to 75 , with an average age of 50,12 years. The mean age at emigration 
was 31,08 years. Participants have spent an average of 19,19 years in Canada with a minimum period of two and a half years.

\section{Design}

Systems theory's focus on the exposition of contextual spirals implies a higher order approach that encourages the search for meta-patterns. As the inclusion of the physical environment in the process of adaptation is a fairly new phenomenon the researchers decided to use a qualitative approach as a means to describe the emigrants' experiential world and to thus discern meta-patterns of environmental experience. Interviews were seen as the appropriate method to 'unfold the meaning of [the immigrants'] experiences, to uncover their lived world' (Kvale, 1996: 1). In an effort to overcome time and cost constraints the researchers gained access to the participants via the Internet.

The initial idea was to conduct interviews via an Internet relay chat program in real time. However, few participants had access to such a program and preferred using e-mail. On further reflection, it was decided to use both e-mail and Internet relay chat programs to gather the data. In order to ensure the effectiveness of the research questions and the Internet as a tool to gather data, a pilot study was conducted. The pilot study consisted of three e-mail participants and two real-time interviews (five participants in total). The pilot study showed that the two open-ended questions did not provide the in-depth information that the researcher expected. The initial two questions were as follows:

(a) How do you experience the physical environment in Canada (this includes both the natural and the built environment)?

(b) How have you or are you still trying to adapt to the physical environment in Canada (this includes both the natural and the built environment)?
These two questions were further developed into the following five questions:

(a) What was your initial experience (when you first arrived) of Canada? Describe your feelings and thoughts in as much detail as possible.

(b) How have you or how are you still trying to adapt to the physical environment in Canada: emotionally and physically?

(c) What were the first things you did in this new environment?

(d) Do you experience Canada as a home? Please qualify your answer by describing why you do or do not experience Canada as a home.

(e) When you think about the physical environment in South Africa, what thoughts and feelings come to mind?

These questions created a context for the answer to include experiences in the socio-cultural and economic environments.

\section{Data analysis}

The data was analysed using a method of content analysis developed in the framework of systems theory outlined by Keeney (1983) and Groenewald (1995). The aim of this method is to uncover meta-patterns by the sequential study of the data on a higher order of analysis. This idea is reflected in a schematic display of the levels of logical typing as it is configured in first order cybernetics (Figure 1.1), second order cybernetics (Figure 1.2) and qualitative data analysis (Figure 1.3).

The data analysis process followed levels of logical typing that were demarcated into first, second and third order steps of analysis as reflected in Figure 1.3 and described below.
Figure 1.1: Levels of logical typing

in first order cybernetics
Figure 1.2: Levels of logical typing

in second order cybernetics
Figure 1.3: Levels of logical typing

in qualitative data analysis
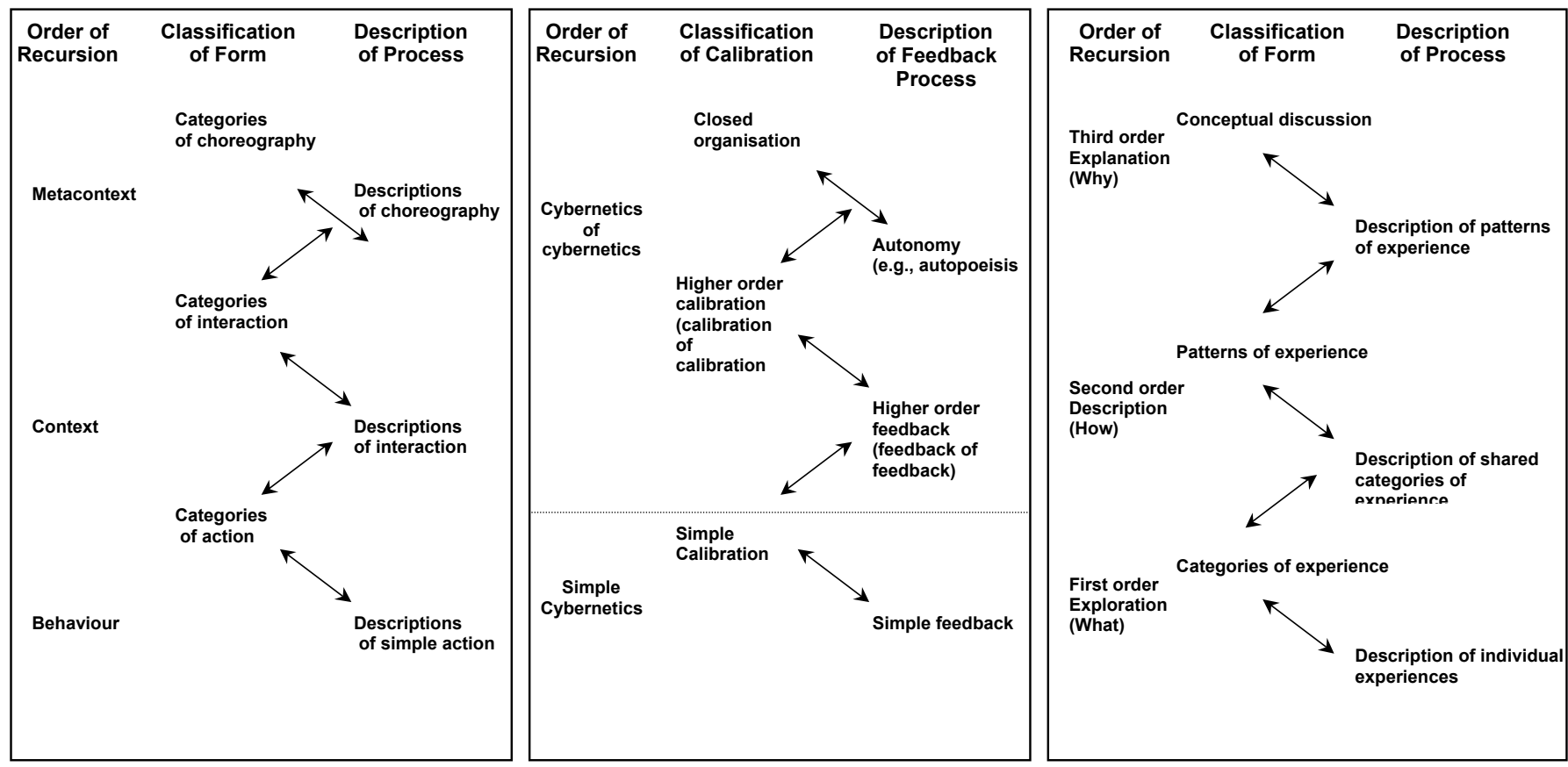
- $\quad$ First order analysis entails:

Step 1: Exploring the data

Step 2: Defining and preliminary labelling of meaningful units of data

Step 3: Labelling of meaningful units of data

Step 4: Establishing the reliability and validity of the coding categories

- Second order analysis entails:

Step 1: Developing and labelling pattern categories

Step 2: Description of pattern categories

Step 3: Establishing the validity of the pattern categories

- Third order analysis entails:

Step 1: Conceptual and theoretical discussion of phenomena under study.

The reliability of the data was determined by means of intraand intercoder reliability as discussed in Miles and Huberman (1994). To establish intracoder reliability the researcher analysed the data twice. Miles and Huberman recommend that the researcher allow for a few days between the first and second analysis. The meaning units and descriptions of the first analysis are compared to that of the second. Intercoder reliability was determined in a similar manner. A random sample of the data was analysed independently by two researchers. The researchers compared the meaning units and descriptions with each other. An intra- and intercoder reliability percentage was determined by the total number of corresponding units from the different analyses divided by the sum of the units. An intracoder reliability of $87 \%$ and an intercoder reliability of $69 \%$ were obtained. The involvement of independent researchers improved the validity of the study as it initiated debate on the relevance of the categories and its content. Kvale (1996: 244) defines this dialogic process as 'testing the validity of knowledge claims in dialogue' and labels it communicative validity. Qualitative research's parallel to reliability, dependability, was also ensured through the peer auditing of the coding process (Bryman, 2004).

\section{Results}

Thirty-six categories of experience were identified. These categories reflect the immigrants' experience of the physical environment in Canada. The categories identified are shown in Table 1 and constitute the first order of data analysis

Table 1: Categories of experience according to frequency of occurrence

\begin{tabular}{|c|c|c|}
\hline & Experience category & Frequency \\
\hline 1 & Experience a feeling of ambivalence: South Africa is also a home & 27 \\
\hline 2 & Mechanisms to adapt to winter & 27 \\
\hline 3 & Canada is experienced as a home & 20 \\
\hline 4 & Experiences of winter & 19 \\
\hline 5 & Exploration & 16 \\
\hline 6 & Experience of place identity & 15 \\
\hline 7 & Experiences of summer & 15 \\
\hline 8 & Thoughts of South Africa stir memories of experiences in SA environment & 15 \\
\hline 9 & Economic conditions & 14 \\
\hline 10 & Experience arousal of emotions when thinking about South African environment & 13 \\
\hline 11 & The importance of social networks & 13 \\
\hline 12 & Looking for housing and creating a home & 12 \\
\hline 13 & Participation in sport & 12 \\
\hline 14 & Experience of the physical characteristics of Canada & 12 \\
\hline 15 & Initial emotional experiences & 11 \\
\hline 16 & Hard work and studies & 11 \\
\hline 17 & Experience of the architectural design of Canadian homes & 10 \\
\hline 18 & The use of language for everyday aspects of the environment differs & 10 \\
\hline 19 & Experience seasons as diverse & 9 \\
\hline 20 & Mechanisms to make optimal use of summer & 9 \\
\hline 21 & Learning the rules of the road & 8 \\
\hline 22 & Maintain ties with South Africa & 8 \\
\hline 23 & Experience the design of the city & 8 \\
\hline 24 & Adaptation is a continuous process over time & 7 \\
\hline 25 & Get involved in cultural activities & 6 \\
\hline 26 & Experience of spring & 6 \\
\hline 27 & Learning the Canadian way of interacting with the environment & 5 \\
\hline 28 & Experience of autumn & 5 \\
\hline 29 & The physical environment in interaction with emotional dispositions & 5 \\
\hline 30 & Come in contact with nature & 4 \\
\hline 31 & Previous experiences and expectations & 4 \\
\hline 32 & Degree to which former activities/interest can be continued & 3 \\
\hline 33 & Deny/avoid the permanence of the move & 3 \\
\hline 34 & Focus on experience of the seasons & 2 \\
\hline 35 & Maintain and foster spiritual activities & 2 \\
\hline 36 & Care of children and animals & 2 \\
\hline
\end{tabular}


Participants most frequently cited feelings of ambivalence and adaptive mechanisms in their interviews. The second and third order descriptions and conceptualisations are discussed below.

\section{Discussion}

Pattern categories are a higher order analysis of the experiential categories described in the previous section and are a reflection of the immigrants' shared experience of the environment. These pattern categories will be discussed in terms of the immigrants' experience of the environment and their consequent coping strategies. Immigrants experience the new environment perceptually, cognitively and emotionally. The ability of an immigrant to achieve goals in the new environment contributes to the emotive content of environmental experiences. Positive evaluations may contribute to evaluating Canada as a home. Exploration of the new environment and interaction with nature may contribute to feelings of being at home and a sense of connectedness with the new environment. In the course of time, immigrants develop a sense of being at home and develop a sense of loyalty toward Canada because of familiarity with the environment. Some immigrants still experience ambivalent feelings, as they perceive both Canada and South Africa as a home.

Although Canada is seen as a home, feelings of outsidedness and unfamiliarity with both the physical and cultural environment and sense of belonging and oneness with South African landscapes can lead to feelings of ambivalence as reflected in this response: 'I think that the way I might best summarise the dichotomy of experience in Canada as both home and not home is to say that Canada is where my home is while South Africa remains my place'. The physical environment is experienced as a space with a unique identity. Even thoughts and memories of the old environment are of a physical external place. Memories of the South African environment are therefore of specific places and landscapes, which forms the context for remembering feelings, activities and people. It seems that there is an inherent emotional connection to the place where one is born and raised, which is evidenced in this statement by a participant: 'There is pure emotion at play when the smell of the red African earth brings tears of remembrance, the sounds of an Africa guitar and kwela pennywhistle brings joyful celebration to one's feet and the sight of a secretary bird transports one to one's youth'. The experience of the environment as an external physical environment is reflected in the immigrants' experience of the built surroundings and the weather. As one participant remarked: 'Winter is an immutable natural law of Canadian existence ... Winter is not an endurance test which you either pass or fail'. The physical environment in Canada is evaluated in terms of the potential it holds for activities. This forms an important component of place identity (Relph, 1976) and as Knez (2005: 209) argues 'climate is nested in places, it not only constitutes objectively a place but also subjectively influences the way we experience and remember a place'. Development of attachment to a new environment does not discredit the feelings of attachment that may be experienced with the old environment. If the immigrant does not develop feelings of belonging to the new environment, but also feels like a stranger in the old environment this may contribute to an overall feeling of rootlessness.
A reciprocal relationship exists between lifestyle and the physical components of an environment which includes the climate (Knez, 2005). The Canadian climate creates a specific context for social interaction. Participation in sport activities forms part of peoples' lifestyle in winter and summer, and is seen as a form of social interaction. Winter is, however, mostly associated with an isolated indoor lifestyle, whereas summer is associated with a socially active and outdoor lifestyle. The physical environment contributes to the economic conditions of a country as reflected in the need to be financially secure to survive the winter climate, to invest in sporting gear and to maximise summer by buying a summerhouse. A society's ecology of ideas regulates interactions and relationships with the environment (Harries-Jones, 2005). South African emigrants in Canada must learn and integrate the Canadian way of interacting with the environment, such as learning a new environmental vocabulary (sidewalk versus pavement, Fahrenheit versus Celsius) and learning the Canadian ways to interact with extreme weather climates.

The built environment regulates social interaction and how immigrants experience the cities, for example, the closely built wooden-structures that contribute to feelings of crowdedness and reduced privacy. The social, political and economic conditions of a country are reflected in the experiences of the environment; some of the immigrants initially have a feeling of unease in the absence of security structures. Knowledge of the historical background of a place can contribute to the extent to which the immigrant feels at home in the new environment. Another example of the interaction between culture and environmental experiences is reflected in the fact that immigrants must adapt to a new road system.

For the purposes of this study Edward's (1992) five categories have been used as a framework in which to interpret the data associated with coping in a new environment. Hereafter follows a discussion of the five pattern categories identified for coping strategies:

Changing the situation refers to an effort to bring the situation in line with the immigrant's needs and plans by either changing his/her perception of reality or by changing the stress components. In an effort to handle the winter climate in Canada immigrants can change the temperature by means of indoor temperature heating devices, by wearing the appropriate winter clothing and by insolating their homes with the correct building material and mechanisms. Components of stress in experiencing the environment can be changed when the immigrant continues previous activities and interests enjoyed in the old environment. The continuation of spiritual activities could also lessen stress experienced in the new environment. Efforts to change a house into a home can be seen as a way to cope with the unfamiliarity of the new environment. Some participants reported using full spectrum lighting to lessen the effect of Seasonal Affective Disorder. This can be viewed as an effort to change the stress component of being exposed to too little sunlight. Finding financial security is another way of changing the economic stresses of a new environment.

Accommodation refers to an effort to bring about changes in the self in order to accommodate to the stressful situation. Although temperature control and the correct winter clothing are a means to change stress associated with cold weather, it 
sometimes creates its own components to which the immigrants must adapt. Accepting the realities of a Canadian winter and managing everyday logistics such as daily contact with the cold weather assists the immigrant in accommodating to the new environment. This process contributes to social integration and emotional adaptation. Learning the Canadian way of interacting with the environment enables the immigrant to accommodate by involvement in cultural activities, such as reading historic literature of a certain place, art and nature conservation. Contact with nature, such as gardening can also contribute to this process as it creates positive feelings of familiarity and belonging. Previous experiences allow a re-interpretation of current experiences of the environment in such a manner that any experience of a European winter would create a context in which Canadian winters are more positively evaluated. A discrepancy between expectations and reality, however, may contribute to stress. Previous experience of Canada and a realistic expectation may contribute to accommodation. Social networks contribute to accommodation, not only by providing a support system, but also as a means by which the immigrant can learn the new society's ecology of ideas.

Devaluation is an effort to minimise the importance associated with discrepancies. According to Perrez and Reicherts (1992) evaluations of the stressful experiences can be changed by adapting attitudes and standards. By having a more positive attitude towards the winter climate and participating in winter activities, the immigrant lessens the stress associated with the Canadian winter.

Avoidance is associated with actions that permit the avoidance of the stressors. Hard work and studies may contribute to accommodating on a social and economic level, but it may allow avoidance of the environmental component of adaptation stress (Edwards \& Baglioni, 1993) when the immigrant avoids outside contact. This may lead to a situation where immigrants do not confront feelings of nostalgia, and may contribute to feelings of rootlessness or they may initially avoid the permanence of the move, which may further prolong the processes of adaptation.
Symptom reduction can be seen as an effort to use behavioural methods that improve overall well-being, referred to by Berry (2006a) as behavioural shifts that generally happen without much difficulty. South African immigrants in Canada lessen their stress symptoms by escaping to warmer climates during winter, becoming involved in cultural activities such as art, visiting South Africa frequently and taking part in activities in nature such as gardening.

The third order analysis can be seen as an effort to uncover metapatterns, by moving to a conceptual discussion of the emigrants' experience of the environment from a systemic point of view. Each immigrant experiences the new environment guided by his/her perceptual, cognitive, emotive, dispositional and the self part-systems. In order to adapt the immigrant undergoes certain changes in these part-systems in order to couple with the surrounding environment. Structural coupling between the immigrant and the new environment is fostered by means of adaptation and acculturation processes, which is in turn reflected in coping strategies. The immigrant's initial experiences of the environment may lead to a stress reaction during which time the immigrant attempts to relieve the stress. With time the immigrant undergoes specific psychological changes similar to somatic changes that can be described as follows: '[t]hrough somatic [psychological] change the organism recaptures some of its flexibility by substituting a deeper and more enduring change for a more superficial and reversible one' (Capra, 1987: 295). If psychological adaption is good these psychological changes will manifest in time as a feeling of being-at-home in the new environment. Genotypical change on a psychological level manifests in the connection that immigrants experience in the new environment based on the ties that family members make with the country. The coordination of behaviour or structural coupling (Maturana and Varela, 1987), between immigrant and environment enables these systems to settle into dynamic patterns of complementary or symmetrical relationships.

Socio-cultural adaptation helps immigrants to manage daily life in their new cultural context (Berry, 2005). Culture and environment form a social system of which the parts function

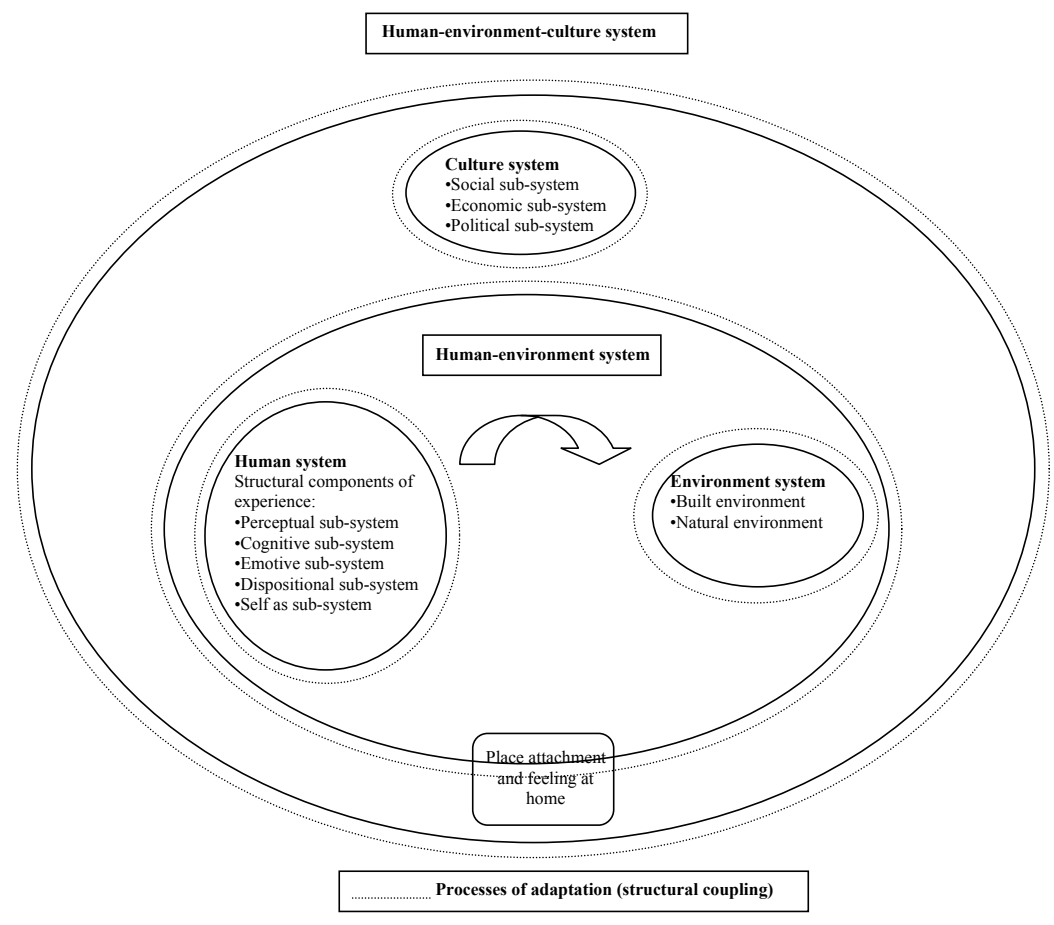

Figure 2: A symbolic representation of the interaction between the systems and the concept of structural coupling by means of adaptation and acculturation processes 
in an integrated manner: '[t]he physical environment influences people and their culture and, in turn, is influenced by them' (Pandey, 1990: 254). The idea of interaction between the systems and the concept of structural coupling by means of adaptation and acculturation processes is reflected in Figure 2 As a component of the acculturation process, structural coupling (good adaptation) must take place between the immigrant and the environment (as indicated in Figure 2). This structural coupling embodies a higher order system namely the human-environment system, i.e. the focus is on the transactions or relations between people and environment. The human-environment system is then placed in a context of a cultural system. Mutual interaction occurs between a cultural system and a physical environment. Socio-cultural aspects are not reflected in the physical environment, but can influence the experience of the environment by regulating the meanings that are attached to these environments. This interaction between person, environment and culture is manifested as a higher order system namely the human-environment-culture system. Structural coupling occurs through processes of adaptation. In this study these processes of adaptation are manifested through stress management strategies. The manner of structural coupling in the human-environment-culture system is reflected in the manifestation of place attachment.

\section{Conclusion}

The physical environment is a fundamental part of adapting to a new setting and should be included as a study unit in acculturation research. The immigrant is also in a reciprocal relationship with the cultural environment where he or she must interact, work and live with others. This research not only contributes to knowledge on adaptation processes, but also contributes to knowledge about human-environment transactions and relationships. This exploratory study provides a framework for future studies. Interdisciplinary research collaboration could contribute to the compilation of a metaprogramme, which state departments and migration agencies could use to prepare migrants for multiple experiences. They would thus not only be informed about the legal/political aspects of migration, but also about the social, economic and physical attributes of the destination country. Given the migration trends across South African borders and this country becoming a safe haven for refugees, acculturation research will provide valuable information for migrant adaptations. The physical environment, built or natural, plays a pivotal role in guiding the immigrant's perceptual, cognitive and emotive disposition toward the new environment.

\section{REFERENCES}

Altman, I. and Chemers, M., 1980: Culture and Environment. Cambridge University Press, Cambridge.

Altman, I. and Low, S.M., 1992: Place attachment: a conceptual inquiry. In: Altman, I. and Low, S.M. (eds.), Place Attachment, pp. 1-12. Plenum, New York.

Amedeo, D., 1993: Emotions in Person-Environment-Behavior Episodes. In: Gärling, T. and Golledge, R.G. (eds.), Behavior and Environment: Psychological and Geographical Approaches, pp. 83-116. Elsevier, Amsterdam.

Ataca, B. and Berry, J.W., 2002: Psychological, sociocultural, and marital adaptation of Turkish immigrant couples in Canada. International Journal of Psychology, 37, 13-26.

Aycan, Z. and Berry, J.W., 1996: Impact of employment-related experiences on immigrants' psychological well-being and adaptation to Canada. Canadian Journal of Behavioural Science, 28, 240-251.

Bakker, W., van der Zee, K. and van Oudenhoven, J.P., 2006: Personality and Dutch emigrants' reactions to acculturation strategies. Journal of Applied Social Psychology, 36, 2864-2891.

Bell, P.A., Greene, T.C., Fisher, J.D. and Baum, A., 2001: Environmental Psychology ( $5^{\text {th }}$ ed.), Harcourt Brace College, New York.

Bennett, H., Rigby, C. and Boshoff, A., 1997: The relationship between tenure, stress and coping strategies of South African immigrants to New Zealand. South African Journal of Psychology, 27, 160-165.

Berry, J.W., 1997: Immigration, acculturation and adaptation. Applied Psychology, 46, 5-68.

Berry, J.W., 2001: A psychology of immigration. Journal of Social Issues, 57, 615-631.

Berry, J.W., 2005: Acculturation: living successfully in two cultures. International Journal of Intercultural Relations, 29, 697-712.

Berry, J.W., 2006a: Mutual attitudes among immigrants and ethnocultural groups in Canada. International Journal of Intercultural relations, 30, 719-734.

Berry, J.W., 2006b: Acculturative stress. In: Wong, P.T.P. and Wong, L.C.J. (eds.), Handbook of Multicultural Perspectives on Stress and Coping, pp. 287-289. Springer, New York.

Berry, J.W., Poortinga, Y.H., Segall, M.H. and Dasen, P.R., 2002: Cross-cultural Psychology: Research and Applications $\left(2^{\text {nd }}\right.$ ed.). Cambridge University Press, Cambridge.

Brehm, J.M., 2007: Community attachment: The complexity and consequence of the natural environment facet. Human Ecology, 35, 477-488.

Brown, G. and Raymond, C., 2007: The relationship between place attachment and landscape values: Toward mapping place attachment. Applied Geography, 27, 89-111.

Bryman, A., 2004: Social Research Methods (2 ${ }^{\text {nd }}$ ed.), Oxford University Press, New York.

Capra, F., 1987: The Turning Point: Science, Society, and the Rising Culture. Flamingo, London. 
Castellanos, E., 2006: Migrant mirrors. The replication and reinterpretation of local and national ideologies as strategies of adaptation by foreign immigrants in Bergamo, Italy. The American Behavioral Scientist, 50, 27-47.

Castles, S. and Miller, M.J., 2003: The Age of Migration: International Population Movements in the Modern World ( $3^{\text {rd }}$ ed.). Guilford, New York.

Edwards, J.R., 1992: A cybernetic theory of stress, coping, and well-being in organizations. Academy of Management Review, 17, 238-274.

Edwards, J.R. and Baglioni, A.J., 1993: The measurement of coping with stress: construct validity of the Ways of Coping Checklist and the Cybernetic Coping Scale. Work \& Stress, 7, 17-31.

Feldman, R.M., 1996: Constancy and change in attachments to types of settlements. Environment and Behavior, 28, 419-445.

Fraser, E.D.G., Maybee, W. and Slaymaker, O., 2003: Mutual vulnerability, mutual dependence. The reflexive relation between human society and environment. Global Environmental Change, 13, 137-144.

Golledge, R.G., 1987: Environmental cognition, in Stokols, D. and Altman, I. (eds.), Handbook of Environmental Psychology (Vol. 1), pp. 131-174. John Wiley \& Sons, New York.

Golledge, R.G., 1991: Cognition of physical and built environments, in Gärling, T. and Evans, G.W. (eds.), Environment, Cognition and Action: An Integrated Approach, pp. 35-62. Oxford University, New York.

Groenewald, A.E., 1995: Toeriste se belewenisse van waterlandskappe in die Nasionale Krugerwildtuin: ' $n$ Ekosistemiese studie, Unpublished Masters Thesis, University of Pretoria

Harries-Jones, P., 2005: Understanding ecological aesthetics: the challenge of Bateson. Cybernetics and Human Knowing, 12, 61-74.

Hidalgo, M. C. and Hernandez, B., 2001: Place attachment: Conceptual and empirical questions. Journal of Environmental Psychology, 21, 273-281.

Jordaan, W. and Jordaan, J., 1998: People in Context (3rd ed.). Heinemann, Johannesburg.

Kaplan, R., 1991: Environmental description and prediction: a conceptual analysis. In: Gärling, T. and Evans, G.W. (eds.), Environment, Cognition, and Action: An Integrated Approach, pp. 19-34. Oxford University Press, New York.

Karanth, K.K., 2007: Making resettlement work: The case of India's Bhadra Wildlife Sanctuary. Biological Conservation, 139, 315-324.

Keeney, B.P., 1983: Aesthetics of Change. Guilford, New York.

Knez, I., 2005: Attachment and identity as related to a place and its perceived climate. Journal of Environmental Psychology, 25, 207-218.

Kosic, A. and Triandafyllidou, A., 2003: Albanian immigrants in Italy: migration plans, coping strategies and identity issues. Journal of Ethnic and Migration Studies, 29, 997-1014.

Kvale, S., 1996: Interviews: An Introduction to Qualitative Research Interviewing. London, Sage.
Lorant, V., Van Oyen, H. and Thomas, I., 2008: Contextual factors and immigrants' health status: double jeopardy. Health \& Place, 14, 678-692.

Markovitzky, G. and Mosek, A., 2005: The role of symbolic resources in coping with immigration. Journal of Ethnic \& Cultural Diversity in Social Work, 14, 145158.

Martikainen, P., Sipilä, P., Blomgren, J. and van Lenthe, F.J., 2008: The effects of migration on the relationship between area socioeconomic structure and mortality. Health \& Place, 14, 361-366.

Maturana, H.R. and Varela, F.J., 1987: The Tree of Knowledge: The Biological Roots of Human Understanding. Shambhala, Boston.

McDonald, T. P. and Pellegrino, J.W., 1993: Psychological perspectives on spatial cognition. In: Gärling, T. and Golledge, R.G. (eds.), Behavior and Environment: Psychological and Geographical Approaches, pp. 4782. Elsevier Science, Amsterdam.

McNeese, C., 2002: Impact of immigration on health and human services: Florida's experience. Social Work in Health Care, 35, 501-522.

Miles, M.B. and Huberman, A.M., 1994: Qualitative Data Analysis: An Expanded Sourcebook (2 ${ }^{\text {nd }}$ Edition). Sage, London.

Nel, P., 1998: Factors Influencing Acculturation and Adjustment of the Expatriate Manager and Spouse, Unpublished MA dissertation, University of Pretoria, Pretoria.

Ng, C.F., 1998: Canada as a new place: the immigrant's experience. Journal of Environmental Psychology, 18, 55-67.

Pandey, J., 1990: The environment, culture, and behavior. In: Brislin,R.W.(ed.),Applied Cross-culturalPsychology: Cross-cultural Research and Methodology Series (Vol. 14), pp. 254-277. Sage, London.

Perrez, M. and Reicherts, M., 1992: A situation-behavior approach to stress and coping. In: Perrez, M. and Reicherts, M. (eds.), Stress, Coping, and Health: A Situation-behavior Approach, Theory, Methods, Applications, pp. 17-38. Hogrefe \& Huber, Seattle.

Rapoport, A., 1982: The Meaning of the Built Environment: A Nonverbal Communication Approach. Sage, Beverly Hills.

Relph, E., 1976: Place and Placelessness. Pion, London.

Reitz, J.G. and Sklar, S.M., 1997: Culture, race, and the economic assimilation of immigrants. Sociological Forum, 12, 233-277.

Savage, M., 2008: Histories, belongings, communities. International JournalofSocialResearch Methodology, 11, 151-162.

Schmidt-Soltau, K. and Brockington, D., 2007: Protected areas and resettlement: what scope for voluntary relocation? World Development, 35, 2182-2202.

Statistics South Africa., 2003: Documented migration. www.statssa.gov.za/publications/statsdownload [accessed 7 Feb 2008]

Stedman, R.C., 2003: Is it really just a social construction? The contribution of the physical environment to sense of place. Society and Natural Resources, 16, 671-686.

Ulrich, R.S., 1983: Aesthetic and affective responses to natural environments. In: Altman, I. and Wohlwill, J.F. (eds.), Behavior and the Natural Environment, pp. 85-125. New York, Plenum. 
Vorkinn, M. and Riese, H., 2001: Environmental concern in a local context. The significance of place attachment. Environment and Behavior, 33, 249-263.

Wapner, S., Kaplan, B. and Cohen, S.B., 1973: An organismicdevelopmental perspective for understanding transactions of men and environments. Environment and Behavior, 5, 255-289.

Ward, C. and Styles, I., 2003: Lost and found: reinvention of the self following migration. Journal of Applied Psychoanalytic studies, 5, 349-367.

Windsor, J.E. and McVey, J.A., 2005: Annihilation of both place and sense of place: the experience of the Cheslatta T'En Canadian First Nation within the context of large-scale environmental projects. Geographical Journal, 171, 146-165.

Zimring, C. and Dalton, R.C., 2003: Linking objective measures of space to cognition and action. Environment and Behavior, 35, 3-16.

Cornel Rademeyer, Claire Wagner and Nafisa Cassimjee Department of Psychology

University of Pretoria

Lynnwood rd, Brooklyn

0181 South Africa 